work of others. There follows a group of paediatric contributions; the first, partly speculative, on the prophylaxis of allergic disease in infancy and childhood and then a useful paper on pollinosis. There are two lengthy chapters by dedicated paediatric allergists on food-induced allergies and gastro-intestinal allergy, a valuable chapter on steroid therapy, and a short chapterthe most succinct in the book by William P. Buffum-on asthma in infancy.

The rest of the book-nearly half-contains further contributions by psychiatrists and psychologists. Abramson introduces and develops his valuable concept of parental engulfment as the basic emotional problem in asthma, and he contrasts it with the psychoanalytic theory of maternal rejection propounded by French and Alexander some 20 years ago. He maintains that the rejection theory does not fully explain all the phenomena -especially that of remission of asthma following 'parentectomy'. He also finds his own concept much more acceptable to parents and, therefore, useful in therapy. There is no doubt that it approximates to the idea of the asthmatic's predicament held by many clinicians in this country.

There follows a fascinating account by $\mathbf{L}$. Bernstein and others of the organization and functions of the psychological services at the Jewish National Home for Asthmatic Children. This Home for 150 children with intractable asthma (that is asthma that has not yielded to any other treatment) is based on the idea of parentectomy. The diagnostic and therapeutic approach is multi-disciplinary. The training and research programmes are impressive. The money needed to finance this gigantic scheme is any one's guess; but this is surely the kind of work that must be done if solid progress is to be made in such a difficult field.

Among the other few chapters, there is one of special interest by M. Murray Peshkin and H. A. Abramson on group therapy in New York with the parents of children in residence in Denver, 2,000 miles away. This gives much insight into what happens with parents when their children are removed from them and what happens when they return some two years later.

This book should be welcomed by paediatricians and child psychiatrists who have a special interest in allergic disease as a truly psychosomatic problem. That is not to say, however, that it is altogether comfortable reading. The papers are variable in quality and they sometimes overlap in content. More detail is given about allergy than is easily assimilable by the average psychiatrist. Asthma, and to a less extent eczema, are most ably dealt with, and the result is impressive. But the gastrointestinal and other allergies have received too little attention from psychiatrists to set against the detailed work done and theories propounded by immunologists.

Some may regret that Abramson has called his parental engulfment theory 'The Cronus Complex'. It is a pity that Oedipal rivalry should lead us further into Greek mythology when our own language can serve so well to express what is meant!

A very full bibliography follows each chapter, but there is no index. Thus, there is a useful chapter on steroid therapy and steroid dependence; but many valuable references to this subject elsewhere can only be found by thumbing through the book.

None the less this book is to be highly recommended to all who are interested in the subject, and Ernest Harms has earned our thanks for this first volume of a series designed to present a multi-disciplinary approach in subjects where this is so clearly needed.

Acute Hemiplegia in Childhood. A Report of a Study Group Held at Clevedon April 20-22, 1961. Little Club Clinics in Developmental medicine No. 6.) Edited by Martin BaX and Ross Mitchell. (Pp. 120; illustrated. 17s. 6d.) London: National Spastics Society (Medical Education and Information Unit) in association with William Heinemann Medical Books, London 1962.

This, the sixth of the enterprising Little Club Clinics in Developmental Medicine, is the report of a small group of paediatricians, neurologists and pathologists who met to discuss all aspects of acute hemiplegia in childhood. There are 14 original papers, and the discussions, which presumably followed each, are condensed and grouped together at the end of the volume. There seem to have been no wild disagreements amongst the participants. The dangers of early carotid angiography are allowed to be small compared with its diagnostic benefits, but what the benefits of exact diagnosis are is unclear.

Dehydration, anticoagulants and hypothermia are fully discussed, but no one of the participants seems to be certain of the circumstances in which any one of these forms of treatment should be used.

Nevertheless the book which contains about 200 references is a useful summary of our present state of ignorance on this baffling subject.

Living with Epileptic Seizures. By SAmuel Livingston. Assisted by Irving M. Pruce. (Pp. xix $+348 ; 11$ figures +21 tables. $\$ 6.50)$ Springfield, Illinois: Charles C. Thomas. 1963.

'The primary purpose of this book' says the author 'is to present pertinent information relative to epilepsy to non-medical persons such as patients and/or their parents, educators and counsellors (sic), as well as to the medical profession.' For the tautological 'pertinent' one should perhaps read 'suitable'; and is it suitable for the recipient of an anti-convulsant drug to know that there are 33 possible outward reactions? The author disarms the writer by stating his belief that the epileptic patient should know as much as possible about the various therapeutic agents and of the recent advances made in the treatment of epilepsy, and by implicitly condemning the practice of concealment. While the reviewer is in general sympathy with this attitude, he cannot help feeling that 'the truth and nothing but the truth, but not necessarily the whole truth' is a useful maxim in doctor-patient relations.

In fact this is a thoroughly useful textbook for the doctor covering all aspects of the epileptics' aetiology 
including heredity, diagnosis, electroencephalography, precipitating factors, general management, drug, dietary and surgical treatment, intellectual and behavioural disturbances, socio-economic and legal consequences (it is a crime for epileptics to marry in some of the United States) and so on. It is written by an expert with 26 years' experience who has made an 'intimate' follow-up study of about 15,000 patients. One thing is clear; if the book is read by only a small proportion of epileptic patients in the U.S.A. it will have to be bought by almost every American doctor.

Die gedeckten Schaden des Gehirns. Experimentelle Untersuchungen mit einmaliger, wiederholter und gehäufter stumpfer Gewalte in Wirkung auf den Schädel. By Friedrich Unterharnscheidt. (Pp. vi $+124 ; 67$ figures. DM. 48.) Berlin, Göttingen, Heidelberg: Springer, Verlag. 1963.

A rapid increase in the accident rate in recent years has stimulated a great deal of interest in the factors playing a part in the production of cerebral lesions following trauma to the head. This monograph describes the results of experiments on 13 rabbits and 46 cats using a concussion gun to produce single or repeated impacts on the skull at velocities ranging from $7 \cdot 1$ to $18 \cdot 3 \mathrm{~m}$. $/ \mathrm{sec}$. Both clinical and pathological effects are discussed, and it is of considerable interest that repeated insults at low velocities produced morphological changes due to vascular disturbances even in the absence of primary traumatic changes. A single impact sufficient to produce unconsciousness did not produce any recognizable changes. Convulsions were also seen particularly amongst the rabbits, and reversible parapareses could be produced by five impacts at a velocity of $7 \cdot 1 \mathrm{~m}$. $/ \mathrm{sec}$. The direction of the impact was also found to be significant.

The booklet should be of interest to those dealing with head injuries as well as to the neurologist who wonders why some of his epileptic patients deteriorate after repeated falls. It could also provide excellent ammunition for those actively engaged in attempts to abolish boxing. It is well produced, but at the price of DM. 48 is unlikely to find its way into many private libraries.

\section{Kinderpsychiatrie in der Praxis. Postgraduate Courses in}

Pediatrics. Edited by E. Rossi. Vol. 9: (Pp. ii +86 . S.Fr./DM. 12.) Basel and New York: S. Karger. 1963.

Child psychiatry in practice is the title of volume 9 of the Postgraduate Courses in Pediatrics. In seven lectures one German and six Swiss child psychiatrists attempt to draft for the practising paediatrician a rough outline of the main problems occupying child psychiatry. They have undertaken an extremely difficult task, and the result is not entirely satisfactory; partly because they lose themselves in commonplace generalizations as in the chapter on the treatment of mental deficiency, or in minutiae of therapeutic ritual in the section on the treatment of psychogenic disturbances in childhood by the practitioner.
It is also hardly justifiable, at our present state of knowledge or rather ignorance, to recommend prolonged administration of spasmolytic or sympathomimetic drugs as curative measures in enuresis.

Interesting is Stutte's view that autism is an entity separate from the general pattern of childhood schizophrenia, and which he regards as a 'constitutional abnormality of the child personality but not as a disease process.' His contribution on psychoses in childhood provides, to the uninitiated, a useful outline of the clinical pictures involved, as do the case notes of 'a psychiatrist in a children's hospital' by Gertrude Sauter.

Hardly any attention is paid to the large borderland between paediatrics and child psychiatry, namely the psychosomatic disorders in childhood, where close co-operation between paediatrician and child psychiatrist is likely to be most fruitful.

This little volume is a brave venture but not a very successful one.

Pathologische Anatomie und Dynamik. Der Plötzliche Kindstod. By G. Müller and E. LetTerer. (Pp. viii +145 ; 55 figures +12 tables. DM. 29.70). Stuttgart: Georg Thieme. 1963.

This monograph is a readable and clear account of the histopathological findings in 98 children who died either suddenly or unexpectedly after an apparently mild illness of not more than $\mathbf{4 8}$ hours. Perinatal deaths are not included. The author confirms the findings of several recent investigators that clinically unimpressive infections of the respiratory tract account for well over half of all these deaths. The observation that there is a marked November to April peak, and that infants under 6 months are the most frequent victims, is confirmed. Nutritional and socio-economic factors appear to be of little significance, whereas lack of maternal experience (mothers aged less than 25 years) was found to be important in the statistical evaluation of the case material.

Cellular changes in the lymphoid tissues, both in the children studied and in experimental animals, lead the author to postulate virus infections as being largely responsible for these deaths. Acute adrenocortical failure, the result of 'stress', is thought to be important. The author confirms that, following a 'stress' situation, a profound and rapid electrolyte disturbance can occur. This in turn is thought to be responsible for the almost constant finding of gross cerebral oedema-the actual cause of death.

Not unexpectedly the mechanics and dynamics of 'stress' are no more clear now than in the days of Selye. The causation of the fatal cerebral oedema also remains more or less a mystery.

The book is well produced on glossy paper and the photomicrographs, both black and white and coloured, are good. There is a truly impressive and commendably international bibliography. Though the author is perhaps a little too concerned with the semantics of 'sudden' as opposed to 'unexpected' death, the book deserves to be widely read. 